\title{
Galectins: an evolutionarily conserved family of animal lectins with multifunctional properties; a trip from the gene to clinical therapy
}

\author{
Gabriel Adrián Rabinovich*,1 \\ 1 Division of Immunology, Department of Clinical Biochemistry, Faculty of \\ Chemical Sciences, National University of Cordoba, Cordoba, Argentina \\ * corresponding author: GA Rabinovich, Avenida Caraffa 2114, 5009, Córdoba, \\ Argentina. \\ fax: 0054-351-4240434; e-mail: gabyrabi@onenet.com.ar
}

Received 21.12.98; revised 6.4.99; accepted 3.5.99

Edited by R. Knight

\begin{abstract}
Galectins constitute a family of evolutionarily conserved animal lectins, which are defined by their affinity for poly-Nacetyllactosamine-enriched glycoconjugates and sequence similarities in the carbohydrate recognition domain. During the past decade, attempts to dissect the functional role for galectins in vivo have been unsuccessful in comparison to the overwhelming information reached at the biochemical and molecular levels. The present review deals with the latest advances in galectin research and is aimed at validating the functional significance of these carbohydrate-binding proteins. Novel implications of galectins in cell adhesion, cell growth regulation, immunomodulation, apoptosis, inflammation, embryogenesis, metastasis and pre-mRNA splicing will be particularly discussed in a trip from the gene to the clinical therapy. Elucidation of the molecular mechanisms involved in galectin functions will certainly open new avenues not only in biomedical research, but also at the level of disease diagnosis and clinical intervention, attempting to delineate new therapeutic strategies in autoimmune diseases, inflammatory processes, allergic reactions and tumor spreading.
\end{abstract}

Keywords: galectins; apoptosis; adhesion; immunomodulation; embryogenesis; metastasis; splicing

Abbreviations: CRD, carbohydrate recognition domain; $E A E$, experimental autoimmune encephalomyelitis; EAMG, experimental autoimmune myasthenia gravis; FasL, Fas ligand; RMGal, rat macrophage galectin; $\mathrm{M} \phi$, macrophages

\section{A biochemical and molecular overview: passport required to galectin research}

Galectins are an enigmatic family of evolutionarily conserved proteins widely distributed in nature from lower invertebrates to mammals. ${ }^{1-3}$ They share sequence similarities in the carbohydrate recognition domain (CRD) in addition to specificity for $\mathrm{N}$-Acetyllactosamine-enriched glycoconjugates. ${ }^{1,2}$ The typical carbohydrate-binding domain consists of 135 amino acids tightly folded into a sandwich structure of 5-6-stranded $\beta$-sheets and recognizes the basic structure of LacNAc; (Gal $\beta 1 \rightarrow 4$ GlcNAc). ${ }^{3}$ Ten mammalian galectins have so far been identified in a wide variety of tissues of several species. ${ }^{4}$ Although this new systematic classification of galectins from 1 to 10 is not extrapolable to non-mammalian galectins, the latter share striking similarities with mammalian galectins at the molecular level. According to their architecture, Hirabayashi and $\mathrm{Kasai}^{5}$ classified this protein family into proto-type, chimera type and tandem-repeat type. Proto-type galectins, include galectins- $1,,^{6,7}-2,{ }^{8}-5,{ }^{9}-7,,^{10}$ human Charcot-Leyden crystal protein, ${ }^{11}$ frog galectins, ${ }^{12}$ electrolectin (the first galectin described); ${ }^{13}$ C. elegans $16 \mathrm{kDa}$ galectin, ${ }^{14}$ chicken isolectins $\mathrm{C}-14$ and $\mathrm{C}-16^{15,16}$ and marine sponge galectins. ${ }^{17}$ Proto-type galectins are non-covalent homodimers composed of two identical CRDs. The best studied among them, galectin-1, formerly referred to as $\mathrm{L}-14$, galaptin and $\mathrm{BHL}$ among other names, has been localized in skeletal, smooth and cardiac muscle, motor and sensory neurons, thymus, kidney and placenta. ${ }^{4}$

On the other hand, chimera-type galectins show a combined structure composed of a carboxy terminal CRD linked to a proline-, glycine-, and tyrosine-rich N-terminal domain. The only member of this family, galectin-3 (previously known as Mac-2, L-29, CBP-35 or IgEBP), has been predominantly found in mammals, ${ }^{18}$ although it has been also identified in chickens. ${ }^{19}$ It has been shown to be expressed by activated macrophages, basophils, mast cells and certain epithelial and tumor cells. ${ }^{18}$

The third family of tandem-repeat galectins are proteins with two distinct CRDs and includes galectins $-4,{ }^{20}-6,{ }^{21}-8^{22}$ and $-9 .{ }^{23}$ Several galectin genes have been cloned and characterized and found to be associated to multiple regulatory elements.

Studies of multiple animal lectins including galectins- 1 and -2 , by X-ray crystallography, have provided evidence for their oligomeric structures. ${ }^{24,25}$ By virtue of their multivalency, these carbohydrate-binding proteins are able to cross-link specific glycoprotein and glycolipid receptors, leading to activation of different signal transduction pathways, which converge in multiple biological responses. ${ }^{26}$ Although the first galectins have been identified by their binding to $\beta$-galactoside-sugars, ${ }^{5}$ the most recently isolated galectins such as galectins -5 and -8 , have been detected by immunoscreening of cDNA expression libraries ${ }^{9,22}$ or through their ability to crossreact with other galectins identified so far. ${ }^{27}$ In this context, galectin-9 was found by 
screening tumor cDNA libraries with sera from tumorbearing patients. ${ }^{23}$

\section{Regulation of galectin expression, subcellular distribution and secretion: a dilemma to be solved}

Galectins have been proposed to play crucial roles by recognizing carbohydrate moieties on intracellular ligands, cell signaling receptors and extracellular glycoproteins, according to subcellular compartamentalization, developmentally regulated expression and cell activation status. ${ }^{28}$ Expression of galectins was found to be up- or downregulated during embryogenesis, being a typical hallmark of specific developmental stages..$^{29}$ Moreover, galectin expression and subcellular distribution have been reported to be highly susceptible to modulation by diverse stimuli such as sodium butyrate, ${ }^{30}$ viral infections, ${ }^{31}$ tumor suppressor genes $^{32}$ or inflammatory agents. ${ }^{33}$ In this review, we will discuss in detail the regulated expression of RMGal, a macrophage galectin-1-like protein, isolated and characterized in our laboratory, which showed immunomodulatory properties. ${ }^{27,34}$

What is the molecular mechanism involved in this regulated expression? Although this question warrants further investigation, a recent study revealed some clues. Gillenwater and colleagues ${ }^{30}$ demonstrated that sodium butyrate, a known differentiating agent was able to modulate galectin-1 content in human head and neck squamous carcinoma cells by a combination of transcriptional regulation and inhibition of histone deacetylation.

Regarding galectin secretion, some critical points must be addressed. From the viewpoint of protein structure, galectins have been designed as proteins intended to play key roles inside the cells; e.g., acetylated $\mathrm{N}$-terminus, lack of secretion signal peptide and biosynthesis on free ribosomes. ${ }^{3,28}$ Indeed, novel intracellular functions have been reported for galectins in the last few years, such as pre-mRNA processing. ${ }^{35}$ However, most of the functions assigned to $\beta$-galactoside-binding proteins are confined to the cell surface or extracellular milieu. ${ }^{28}$ An evolutionary explanation of this picture could be raised by speculating that galectins acquired extracellular functions in the course of the development of multicellular metazoan organisms, but their original tasks were confined to intracellular environments in primitive organisms. ${ }^{4}$ Nevertheless, the mechanism by which these cytosolic proteins are targeted to subcellular compartments and exported to the extracellular space still remains to be elucidated. Concerning the externalization of galectin-1, two hypothesis have been proposed. One likely explanation is the utilization of specific transmembrane carriers, like those used to export some bacterial toxins. ${ }^{36}$ The second hypothesis considers the possibility that galectin-1 could be secreted by a novel apocrine mechanism, in which the synthesized protein becomes concentrated at the level of plasma membrane evaginations prior to secretion and further externalized to form galectin-enriched extracellular vesicles. ${ }^{28}$ Recently, Mehul and Hughes ${ }^{37}$ demonstrated that the rate-limiting step for galectin-3 secretion is the trafficking from biosynthetic sites to the plasma membrane and that the signal for secretion lies in the $\mathrm{N}$-terminal domain of the lectin. Furthermore, they provided evidence that galectin-3 is externalized in vesicles and released into the extracellular medium. A kind of unfrequent mechanism of externalization is also used by many cytokines and growth factors. $^{38}$

Galectins can be targeted and secreted to exert their functions by interacting with intracellular and extracellular glycoconjugates. Subcellular targetting of these proteins to different intracellular compartments was found to be an additional level of modulation by diverse stimuli. Translocation of galectin-3 to the nucleus was evident when quiescent fibroblasts were exposed to growth factors. ${ }^{39}$ Moreover, its secretion was induced in activated but not in resident macrophages. ${ }^{33}$

\section{Unraveling the puzzle of galectin functions: the main stop of the trip!}

Attempts to dissect the functional roles for galectins in vivo have been unsuccessful in comparison to the overwhelming information reached at the biochemical and molecular levels. Targeted disruption of galectin-1 and -3 genes in single or double knock out mice resulted in the absence of major phenotypic abnormalities, ${ }^{40,41}$ suggesting that other members of this family could potentially compensate for the absence of these proteins, as suggested for null mutations in particularly important genes. Nevertheless, their conservation throughout animal evolution and their widespread distribution, strongly suggest they could be critical for life. Identification of novel pleiotropic functions for this protein family has attracted the attention of many investigators in the last few years, raising many exciting questions.

What is the functional need for creating multiple genes encoding galectins that seem to recognize broadly similar arrays of carbohydrate epitopes within each family? One likely explanation is related to differences in carbohydratebinding specificities, as has been established for several galectins. ${ }^{4,42}$ On the other hand, redundancy is often built into mechanisms operating in key events during development as a form of fail-safe insurance. ${ }^{43}$

Galectins have been implicated in several physiopathological processes requiring carbohydrate recognition, such as cell adhesion, ${ }^{28}$ cell growth regulation, ${ }^{44,45}$ immunomodulation, ${ }^{46,47}$ apoptosis, ${ }^{34,48,49}$ inflammation, ${ }^{50}$ embryogenesis, $^{29}$ reproduction, ${ }^{51,52}$ tumor spreading ${ }^{53,54}$ and premRNA splicing. ${ }^{35,55}$ The precise knowledge of the mechanism of action of galectins is lacking, although their effects are believed to relate to interactions with specific carbohydrate ligands. It should be emphasized that the vast majority of galectin functions have been assigned to galectins-1 and -3 . In contrast, functions corresponding to other members of this protein family are still a virgin land, and remain to be elucidated in future work. The present review deals with the latest advances in galectin research and is aimed at validating the concept of an in vivo role for this evolutionarily conserved protein family and its implications in biomedical research and clinical therapy. 


\section{Galectins in cell-cell, cell-matrix interactions: to stick or not to stick?}

Adhesion and migration of cells through basement membranes and the extracellular matrix (ECM), is a multistep process coordinated by receptors recognizing a mosaic of ECM glycoproteins, haptotactic chemokines and pro-inflammatory cytokines. ${ }^{56}$ In this context, galectins are secreted into the extracellular millieu, where they recognize poly- $N$ acetyllactosamine chains on major ECM components. ${ }^{28}$ Consistently, a variety of extracellular and intracellular candidate ligands have been reported to bind galectins, such as laminin, ${ }^{57}$ fibronectin, ${ }^{58}$ lysosome-associated membrane proteins 1 and 2 (LAMP-1 and 2) ${ }^{59}$ and CD45. ${ }^{48}$ In view of this specific recognition, galectins have been postulated as powerful modulators of cell-cell and cell-ECM interactions. Controversial results have been reported as to whether galectin-1 exerts a positive or a negative effect on cell adhesion to ECM glycoconjugates, raising the possibility that this homodimeric protein could promote cell attachment or detachment according to the cell type or cell developmental stage. ${ }^{28}$ The presence of galectin-1 inhibited myoblast interaction with laminin by sterically blocking the laminin receptor $\alpha_{7} \beta_{1}$ integrin from recognizing laminin, thus allowing myoblasts to fuse into myotubes. ${ }^{60}$ Moreover, we have recently shown that galectin-1 specifically inhibited $\mathrm{T}$ cell adhesion to ECM glycoproteins. This effect correlated with the ability of this molecule to prevent the re-organization of the activated T cell's actin cytoskeleton. ${ }^{61}$ On the other hand, galectin-1 showed pro-adhesive properties on other cell types, such as melanoma cell lines, ${ }^{62}$ F9 murine embryonic teratocarcinoma cells, ${ }^{57}$ olfactory neurons, ${ }^{63}$ rhabdomyosarcoma cells ${ }^{58}$ and $\mathrm{CHO}$ fibroblasts. ${ }^{57}$ Interestingly, to exert these stimulatory effects, dimeric galectin-1 acted by bridging oligosaccharides between specific cell surface glycoconjugates and ECM components. Similarly, the effects of galectin3 on cell adhesion were conflicting, depending on the physiopathological environment. While this chimeric protein promoted neutrophil adhesion to laminin in the context of an inflammatory response, ${ }^{64}$ it showed a dramatic inhibitory effect on melanoma cell adhesion to ECM in a threatening situation of tumor spreading. ${ }^{65}$ Hence, what is the biological significance whereby the same endogenous protein can exert completely opposite effects according to different physiopathological situations? Further investigations will be needed to clarify these findings.

\section{Galectins in cell growth regulation: how to bias the equilibrium?}

In multicellular organisms, homeostasis is maintained through a delicate balance between cell proliferation and cell death. ${ }^{66}$ In addition to promoting or inhibiting cell attachment in the context of the ECM, galectins have been also reported to exert critical but contradictory effects on cell growth. A mitogenic effect towards vascular cells has been reported for galectin-1 during alveolarization of post-natal rat lung. ${ }^{67}$ On the other hand, Wells and Mallucci ${ }^{44}$ demonstrated that galectin-1 acted as a powerful autocrine cytostatic and negative growth factor in murine embryonic fibroblasts, by arresting the cell cycle at G0 and G2 check points. Implications of galectin-1 in cell growth arrest and apoptosis in the context of the immune system will be discussed in detail in the next section.

To reconcile these findings, an interesting activity of galectin-1 as a biphasic modulator of cell growth has been reported. ${ }^{45}$ While this $\beta$-galactoside-binding protein was found to be mitogenic at low physiological concentrations, growth-inhibitory properties were apparent in a higher concentration range, when tested on human cells in vitro. Thus, the effects of galectin-1 seem to be double-edged, since it may trigger either proliferation or cell growth arrest, depending on the presence of concomitant environmental signals, dose, cell cycle stage, or the expression of carbohydrate receptors on the cell surface. ${ }^{45}$ It should be highlighted that the concept of a bifunctional protein with both growth-stimulatory and growth-inhibitory activities is not limited to galectins. Other signaling molecules such as TGF- $\beta{ }^{68}$ and FasL, ${ }^{69}$ have been shown to trigger different effects depending on the type and functional state of the cell. Indeed, the interaction of positive and negative signals to maintain homeostasis is compatible with the basic yinyang principle of the universe.

\section{Galectins in the immune system: the missing link?}

Research over the past decade identified immunomodulatory properties for galectin-1 in the context of two experimental models of autoimmune disease. Administration of recombinant galectin-1 prevented clinical and histopathological signs of experimental encephalomyelitis (EAE), a T-cell-mediated autoimmune disease in susceptible Lewis rats. ${ }^{47}$ Moreover, an homologous galectin from the fish Electrophorus electricus showed prophylactic and therapeutic effects on experimental autoimmune myasthenia gravis (EAMG) in rabbits. ${ }^{46}$ Although the precise mechanisms involved in these properties in vivo still remain to be elucidated, it has been proposed that galectin-1 may affect processes in T-cell suppressor commitment and in sensitization or deletion of antigenspecific T cells. ${ }^{46,47}$ Particularly attractive, experimental data have been accumulated in the last few years, concerning the implications of galectin-1 in apoptosis of mature T cells ${ }^{34,48,52}$ and immature cortical thymocytes. ${ }^{70}$ It may also be relevant that autoantibodies against galectin-1 have been demonstrated in sera of patients with neurological disorders, particularly those suffering from multiple sclerosis. ${ }^{71}$

The conceptual idea that a carbohydrate binding protein could affect the apoptotic threshold of $T$ cells, not only provided a breakthrough in galectin research, but also revolutionized the field of glycoimmunology. Consequently, in the next section we will entirely concentrate on this novel function and its potential implications in health and disease.

The second evidence supporting the idea that these versatile proteins could be implicated in the regulation of adaptive immune responses comes from the striking localization of galectin-1 in immune privileged sites of the body, such as the placenta ${ }^{6,52}$ and the eye, ${ }^{72}$ where multiple factors operate to ensure rapid elimination of inflammatory cells. T-cell apoptosis would hence provide a 
sophisticated, naturally occurring mechanism to confer protection to vulnerable sites from tissue damage. Recent studies have shown that expression of FasL in sites of immune privilege may have a key role in preserving this privilege by selectively killing activated $\mathrm{T}$ cells by apoptosis. ${ }^{73}$ Accordingly, one might speculate that galectin-1 represents an alternative regulatory signal to regulate mechanisms operating in the establishment of immune privilege. Expression of this protein in first term gestation placenta, could be significant in protecting the fetus from the immune system of the mother by killing infiltrating $T$ cells. ${ }^{52}$ Moreover, galectin-1 expression in the context of the eye would protect this sensory organ from the devastating effects of an inflammatory response. ${ }^{73,74}$ In addition, a protein related to the galectin family called GRIFIN (galectin-related interfiber protein) was recently found in lens by cDNA display techniques. ${ }^{72}$ These protein may contribute to the process whereby cells in the lens become apoptotic and filled with the clear protein, cristallin.

Galectin-1 has also been identified not only in peripheral lymphoid organs such as lymph nodes ${ }^{75}$ and spleen, ${ }^{27,76}$ but also at the level of central thymic microenvironment, where thymocyte education takes place. ${ }^{77}$ Human thymic epithelial cells synthesize galectin-1, which binds to oligosaccharide ligands on the surface of thymocytes. ${ }^{77}$ The degree of galectin-1 binding to thymocytes correlated with the maturation stage of the cells, as immature thymocytes bound more galectin-1 than did mature thymocytes. This result suggests one mechanism for the influence of thymic epithelial cells in positive selection of thymocytes bearing the appropriate T-cell receptor and in negative selection of autoaggressive clones. Taken together, these observations strongly support the idea that galectins could be critical regulators in the generation, maintenance and restoration of central and peripheral immune tolerance.

In the last few years, new advances have extended the interface between glycobiology and immunology. Recently, using a mRNA display PCR to search for genes induced in activated $T$ cells, galectin-1 gene expression was found to be strongly upregulated in effector $\mathrm{T}$ cells. ${ }^{78}$ This protein was able to inhibit antigen-induced proliferation of naive and memory $T$ cells, acting as an autocrine negative growth factor. When this inhibitory mechanism was investigated in detail, it was confirmed that galectin-1 switched off $T$ lymphocyte effector functions, by arresting cell cycle progression at the level of the $S$ and $G_{2} / M$ stages and alternatively triggering IFN- $\gamma$-mediated apoptosis of activated human $\mathrm{T}$ lymphocytes. ${ }^{79}$

In addition to the immunosuppressive and inhibitory functions reported here for galectin-1, recent studies have shown that galectin-3, formerly defined as an IgE-binding protein, was able to inhibit IL-5 gene transcription and protein release from human eosinophils and allergenspecific $T$ cell lines. ${ }^{80}$ The possibility to shut down the IL5 pathway opens new avenues in the regulation of the $T$ helper 2-dependent allergic reactions. Further investigations will be needed to clarify the mechanisms involved in this process. Finally, a recent study has also postulated a role for galectin-3 in early events of the immune response by optimizing cell-cell contact and antigen presentation between professional dendritic cells and naive lymphocytes. $^{81}$

Finally, a crucial question must be inevitably raised. Are galectins essential for the immune response to such a degree to be considered 'the missing links', or are they mere 'supporting actors', acting as redundant proteins? Undoubtedly, a main challenge for future work.

\section{Galectins: a novel paradigm in the regulation of programmed cell death}

The first clue indicating that a $\beta$-galactoside-binding protein could be associated with apoptosis was provided by Goldstone and Lavin in $1991,{ }^{82}$ who reported that the galectin-1 gene was overexpressed during glucocorticoid-induced cell death.

Apoptosis occurs in a wide variety of specific physiological situations and plays a crucial role in normal tissue homeostasis. $^{66,83}$ Although diverse signals can induce apoptosis in a wide variety of cell types, a number of evolutionarily conserved genes regulate a final common cell death pathway that is preserved from worms to humans. ${ }^{66,74}$ Of particular relevance to the immune system, cell death programs promote tolerance by deletion of autoreactive lymphocytes in the central lymphoid organs and termination of immune responses in the peripheral immune system. Gene knock out experiments in mice have failed to identify unique receptors necessary for apoptosis in the thymus other than the $\mathrm{T}$ cell receptor and glucocorticoids. In the context of novel molecules involved in central death machinery, galectin-1 expressed by human thymic epithelial cells ${ }^{77}$ has been recently shown to induce apoptosis of immature cortical thymocytes. ${ }^{70}$ Two subpopulations were particularly susceptible to galectin-1induced apoptosis: the first corresponding to non-selected thymocytes bearing the immature phenotype $C D 3^{-} \mathrm{CD} 4^{\text {low }}$ CD8 ${ }^{\text {low }} \mathrm{CD}^{-} 9^{-}$and the second corresponding to a negatively-selected population of $\mathrm{CD} 3^{\text {int }} \mathrm{CD} 4^{\text {low }} \mathrm{CD} 8^{\text {low }}$ $\mathrm{CD}^{-} 9^{-}$thymocytes. ${ }^{70}$ Hence, galectin-1 is the ideal candidate to be second apoptotic signal required for TCRmediated negative selection. Vespa et $a{ }^{84}{ }^{84}$ have recently demonstrated that galectin-1 specifically modulates TCR signals to enhance TCR-mediated apoptosis. The model of galectin-1 gene knock out mice ${ }^{40}$ will be useful for the elucidation of the precise role of galectin-1 in the elimination of non-selected and negatively selected cells during thymocyte development.

$T$ cells that emerge from the thymus contain not only a wide repertoire of foreign antigen receptor specificities, but also potentially autoaggresive clones that were not eliminated during central tolerance. ${ }^{74}$ These potentially autoreactive clones are then subjected to peripheral tolerance. Activation-induced cell death of mature peripheral $\mathrm{T}$ cells is indeed one of the mechanisms aimed at the elimination of dominant autoagressive clones. ${ }^{74,85}$ Those clones may die by fratricide or suicide mediated by FasFasL or TNF-TNFR1 interactions. ${ }^{74}$ In this context, galectin1 has been also reported to induce apoptosis of mature $T$ cells. ${ }^{34,48,52,86}$ Interestingly, the apoptotic effect of soluble 
galectin-1 depended upon the activation state of $\mathrm{T}$ cells. Perillo and colleagues ${ }^{48}$ clearly demonstrated that galectin1 induced apoptosis of mature T cells bearing the CD45RO splicing product, which was found to be differentially glycosylated. ${ }^{87}$ Although CD45 in general was found to be essential for transducing death signals generated by galectin-1, the glycosylation state of this phosphatase receptor might modulate cell susceptibility to apoptosis. This provides an alternative mechanism for explaining the immunosuppressive properties exhibited by this highly conserved protein family. Apoptosis would hence be an ideal, non-inflammatory mechanism to terminate autoimmune T-cell attack, assuring a minimum of detrimental bystander damage to the local parenchyma. ${ }^{85}$

Regarding cell death regulation, overall opposite functions from galectin-1 have been assigned to galectin-3, providing clues to a novel paradigm. While galectin-1 has been shown to induce T-cell apoptosis, ${ }^{34,48,52}$ galectin-3 has been conversely shown to prevent cell death. ${ }^{49}$ Thus, galectins- 1 and -3 may represent an additional family of proteins similar to the $\mathrm{Bcl}-2$ family, where different members exhibit sequence similarity, yet opposite effects on cell survival. Whereas $B c /-2$ and $B c /-X_{L}$ are negative regulators of apoptosis, $B a x, B a d$, and $B a k$ contribute to a positive signal in the regulation of cell death. ${ }^{88}$ Transfection of galectin-3 cDNA into leukemia $T$ cells conferred resistance to apoptosis induced by Fas ligation and by staurosporine. ${ }^{49}$ Of particular interest, galectin-3 showed a significant sequence similarity to $\mathrm{Bcl}-2$, mainly concentrated in the functional BH1 (NWGR) domain. Moreover, substitution of glycine to alanine in this motif completely abrogated its antiapoptotic activity. ${ }^{89}$ It should be pointed out that the apoptotic activity of galectin-1 was demonstrated using an exogenous protein, which bound to cell surface glycoconjugates, whereas for galectin-3, the anti-apoptotic activity was shown with transfected cells in which the protein likely exerted its functions intracellularly. Moreover, other members of the galectin family may show redundancy in these pro- and anti-apoptotic effects. Indeed, it has been recently demonstrated that galectin-9, a novel tandemrepeat lectin, is able to trigger apoptosis of murine thymocytes. $^{90}$ Elucidation of the biochemical pathways and intimate mechanisms that regulate galectin-induced apoptosis will offer a remarkable opportunity to manipulate life-and-death decisions of the cells and more importantly will provide far-reaching implications for the future health of autoimmune patients. Finally, biomedical research should focus attention on other disorders associated with inhibition of apoptosis, such as cancer and viral infections and diseases associated with increased apoptosis such as neurodegenerative disorders, AIDS and ischemic injury.

\section{Galectin-1 in activated macrophages: lethal weapon for the common good?}

Macrophages $(\mathrm{M} \phi)$ function at different levels of the immune response, either as scavenger, cytotoxic, regulatory or antigen presenting cells. ${ }^{18,91}$ Because galectin-1 had shown such immunomodulatory properties, we wondered whether it would be possible to identify its presence in key immunor- egulatory cells, such as $\mathrm{M} \phi$ and further prove its functional significance toward target cells.

By means of immunochemical and immunocytochemical studies, we have identified the presence of a $15 \mathrm{kDa}$ soluble protein with key features of mammalian galectin-1 in rat peritoneal $\mathrm{M} \phi$ using a polyclonal antibody raised against the extensively studied $\mathrm{C}-16$ chicken isolectin. ${ }^{27}$ The rat macrophage galectin (RMGal) was purified from chemically activated macrophages by single step affinity chromatography on a lactosyl-Sepharose matrix, resulting in the isolation of a sharp protein band of $15 \mathrm{kDa}$, an isoelectric point of 4.8 and high hemagglutinating activity specifically inhibited by saccharides bearing a $\beta$-D-galactoside configuration. ${ }^{34}$ This protein behaved as a homodimer under nondenaturing conditions, and internal amino acid sequence revealed extensive homologies (80-90\%) with other members of the galectin-1 subfamily. Taken together, all of the described properties resembled those exhibited by mammalian galectin-1. Interestingly, a recent study ${ }^{92}$ extended our findings, reporting that cell surface galectin1 -like protein was associated with complement receptor 3 (CR3), a member of the $\beta_{2}$-integrin family.

Macrophages are highly adaptive cells able to modify their behavior in response to different environmental signals. ${ }^{18}$ In this sense, resident, inflammatory or chemically-activated $\mathrm{M} \phi$ must be viewed as distinct cell subpopulations, since they show different phenotypes according to their activation status. These up- or downregulated receptors or enzymes are closely related to their functional competence. Hence, peritoneal exudate $\mathrm{M} \phi$ harvested after i.p. injection of inflammatory agents, such as proteose-peptone are heterogeneous in comparison to resident $\mathrm{M} \phi \mathrm{s}$, which are quiescent cells, and are also distinct from $\mathrm{M} \phi$ chemically-activated with phorbol esters or chemotactic peptides.

In the light of this observation, the next question we attempted to elucidate was related to the regulation of total and surface expression of RMGal in different $\mathrm{M} \phi$ subpopulations. By Western blot analysis and further densitometric quantitation, we found a fivefold increase in total galectin expression in chemically activated $\mathrm{M} \phi$, and a twofold increase in inflammatory $\mathrm{M} \phi$ in comparison to resident peritoneal cells (Figure 1, left panel). Moreover, modulation of RMGal expression was accompanied by an increase in cell surface immunostaining as shown by FACS analysis of non-permeabilized cells. ${ }^{27}$ Modulation of galectin expression and subcellular distribution validated the concept that this molecule could indeed be implicated in critical immunological processes mediated by $\mathrm{M} \phi$. By using current techniques to evaluate apoptosis, such as TUNEL assay, transmission electron microscopy and DNA fragmentation analysis (Figure 1, right panel), we concluded that RMGal was clearly involved in apoptosis of mature T cells and that this effect was dependent on its carbohydrate-binding properties. ${ }^{34}$

Several observations support the idea that cells from the monocyte-M $\phi$ lineage regulate immune function by controlling T-cell death. FasL from antigen-presenting cells was able to mediate cognate T-cell apoptosis, as shown for HIV infection. ${ }^{93}$ Even monocytes and dendritic cells 
from peripheral blood of healthy individuals can induce apoptosis of mitogen-activated $\mathrm{T}$ cells. ${ }^{93}$ Hence, RMGal could be seen as a lethal weapon, an alternative $\mathrm{M} \phi$ signal to induce cell death. As galectin-3 (Mac-2 antigen) was previously found in thioglycollate-elicited $\mathrm{M} \phi,{ }^{33}$ the interplay between these homologous proteins within the same cells should be interpreted in terms of the paradigm discussed above.

\section{Galectins modulate different steps of the inflammatory cascade}

That galectins could play important roles in inflammatory processes was first suggested for galectin-3, which was described as an antigen (Mac-2) expressed on the surface of thioglycollate-elicited peritoneal $\mathrm{M} \phi .^{33}$ This observation was strengthened by our findings that RMGal was differentially expressed in inflammatory and activated $\mathrm{M} \phi{ }^{27}$ Whatever their mechanisms of action at the molecular level, galectins are supposed to modulate inflammation acting in an autocrine or paracrine fashion.

Participation of galectins in inflammation is not limited to adhesion and migration and could be extended to the regulation of the respiratory burst and leukocyte chemotaxis. Galectin-3 has been reported to activate the NADPHoxidase and stimulate superoxide production from peripheral blood neutrophils, but only if they were pre-treated with cytochalasin B, which facilitated degranulation by disrupting the microfilament system. ${ }^{50}$ This study has been recently undertaken by Karlsson et al, ${ }^{94}$ who concluded that galectin-3 was able to activate NADPH oxidase in exudated but not in circulating neutrophils. Hence, galectin-3 could be viewed as a potent stimulus for the neutrophil respiratory burst, provided that the cells have previously experienced extravasation.

Galectin-3 knock out mice were also evaluated to test the effect of gene targeting toward an inflammatory challenge in a model of acute peritonitis. ${ }^{95}$ Four days

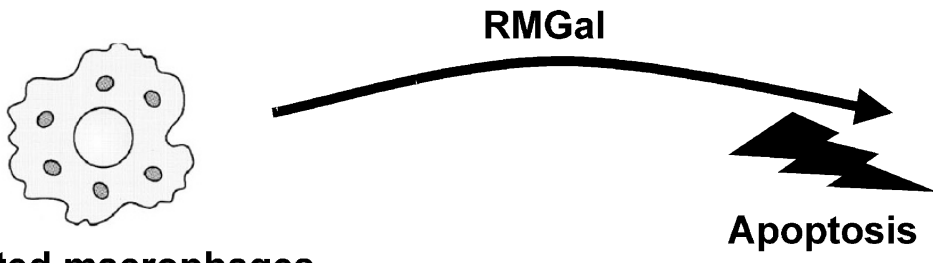

Activated macrophages

A)

$$
\text { है }
$$

窘
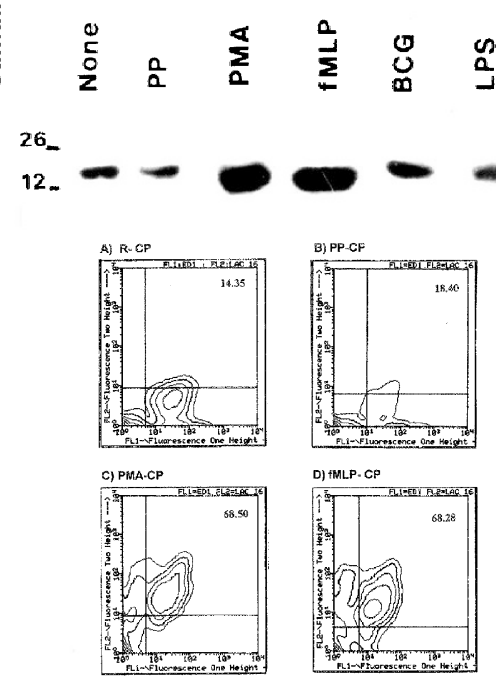

B)

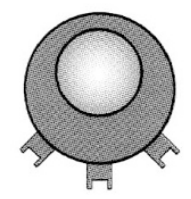

Mature T-cells

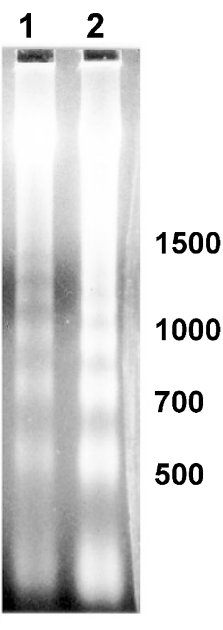

Figure 1 Galectin-1, an alternative signal in the regulation of T-cell death, is increased in activated rat macrophages. In search for mediators involved in M $\phi$ induced T-cell apoptosis, a galectin-1-like protein (RMGal) was purified from rat peritoneal $\mathrm{M} \phi$ and its expression was found to be differentially regulated in resident, inflammatory and activated $\mathrm{M} \phi$. Panel (A) (left): Western blot analysis of peritoneal $\mathrm{M} \phi$ exposed to different stimuli. Phorbol esters (PMA) and chemotactic peptides (fMLP) induced a dramatic increase in RMGal expression in comparison to resident $M \phi$ (none) and to those inflammatory $M \phi$ elicited with proteose-peptone (PP), lipopolysaccharides (LPS) and bacillus Calmette-Guérin (BCG). This increase was accompanied by a modulation of surface expression of this protein as evidenced by FACS analysis. Dual parameter counter plots from resident (R), inflammatory (PP) and activated (PMA and FMLP) M $\phi$ are shown on the bottom left panel. Increasing green fluorescence intensity (ED1: M $\phi$ marker) is plotted on the $x$ axis versus increasing red fluorescence intensity (anti-galectin $\mathrm{Ab}$ ) on the $y$ axis. Panel (B) (right): RMGal induced apoptosis of mature T cells, as shown by DNA fragmentation (inset lane 1: RMGal; lane 2: Con A plus RMGal) and TUNEL assay (inset A: Con A plus RMGal; B: RMGal). Details are included in the text. Insets reproduced with permission from: J. Leuk. Biol. (1996) 59: 363370. Copyright 1996, Society of Leukocyte Biology and from J. Immunol. (1998) 160: 4831-4840. Copyright 1998, The American Society of Immunology 
after thioglycollate injection, galectin-3 mutant mice exhibited a reduced number of granulocytes compared to wild-type mice, suggesting that this protein could be involved in the control of acute inflammation in vivo. In the context of newly discovered galectins, ecalectin, a variant of human galectin- 9 , has been recently proposed as a novel eosinophil chemoattractant produced by $T$ lymphocytes. ${ }^{96}$ This is particularly important in terms of inflammatory diseases mediated by eosinophil accumulation, such as bronchial asthma, rhinitis and atopic dermatitis. Finally, a novel role has been recently assigned to galectin-3 in atherogenesis. ${ }^{97}$ Since atherosclerosis is considered as an inflammatory-proliferative response of the intima layer, the striking localization of galectin-3 in carotid atherosclerotic lesions mainly in $\mathrm{M} \phi$ and foam cells, warrants future investigation.

\section{Galectins in embryogenesis and reproduction: a tour of the origins of life}

Developmentally regulated expression of $\beta$-galactosidebinding proteins strongly suggest they could play important roles during embryogenesis. ${ }^{5}$ Transcripts for galectins-1 and 3 were identified at early stages of embryo development, particularly at the level of the uterine wall. ${ }^{29}$ Gene expression for both galectins was limited to trophectoderms, external structures able to make the first contact with the uterus. After gastrulation, galectins- 1 and -3 did not overlap, and followed a distinct pattern of expression.

To investigate the role of these proteins during embryogenesis, knock out mice were generated ${ }^{40}$ with targeted deletions in galectins-1 and -3 . Both galectin-1 $(-/-)$ or galectin-3 ( $-/-)$ homozygous null mutant embryos implanted successfully and newborn mice appeared to develop normally. Adult mutant mice were fertile and did not harbor any critical phenotypic difference in comparison to wild-type siblings. Several conclusions could be drawn from this experiment. At first sight, it seems that galectins- 1 and -3 may be dispensable for mouse development, raising the possibility that other proteins (perhaps members of the same family), could potentially compensate for their absence, as mentioned above. Indeed, galectin-5 has also been found to be expressed at early stages of embryonic implantation. ${ }^{41}$ Moreover, double mutant mice for galectins -1 and -3 were recently generated, but again did not show any overt abnormalities in their phenotypes. ${ }^{41}$

Nevertheless, it is important that individual knock out mice should be carefully examined for subtle differences in other physiological systems regardless of their viability. By virtue of its implications in apoptosis, one might expect that knock out mice for galectin-1 would have autoimmune manifestations, such as lupus-like disorders, as observed in MRL Ipr/lpr or $\mathrm{C} 3 \mathrm{H}$ gld/gld mice with mutations in Fas and FasL genes respectively. ${ }^{98}$ Transgenic mice carrying a dominant negative galectin-1 targeted to different tissues should certainly provide some clues. Recently, the only defect in galectin-1 mutant mice was revealed at the level of primary olfactory neurons, in the connections between the nasal cavity and the olfactory bulb, suggesting a role for galectin-1 in the olfactory nerve pathway. ${ }^{99}$ Interestingly, growth retardation and early death have been reported in knock out mice for the $\beta$-1,4-galactosyltransferase enzyme, which functions by transferring galactose residues to backbone sugar structures, excellent ligands for galectins. ${ }^{100}$ This result needs further consideration to be reconciled with the implied involvement of galectins in the regulation of programmed cell death.

Expression of apoptotic galectin-1 and mitogenic galectin-3 is differentially regulated throughout mammalian gestation. ${ }^{51,52}$ Galectin-3 was found to be dramatically decreased in term ovine placenta, with respect to the middle of the gestation period. In contrast, no significant decrease was observed in galectin-1 expression. Regulated expression throughout development and differential localization in the uteroplacental complex, ${ }^{101}$ strongly imply that galectins may be critical in embryogenesis and reproduction, and justify our short trip to the origins of life.

\section{Galectins in multistep tumor spreading: seeing the woods for the trees}

Metastasis is a multistep process involving detachment of tumor cells from primary sites, angiogenesis, invasion through blood vessels into the circulation and attachment to newly colonized tissues. ${ }^{102}$ Benefits from unraveling the wood of the metastatic cascade, will only come from a better understanding of every tree at the molecular level. Here again, endogenous galectins have been implicated in neoplastic transformation and metastasis of certain human and experimental tumors. ${ }^{53}$

The tumorigenic potential of galectins has not been studied in such detail as their role in tumor invasion. In this sense, a critical contribution has been made by Gaudin et $a{ }^{32}$ who revealed that galectin-3 gene expression was upregulated by growth factors and oncogenes and downregulated by transfection of the wild-type p53 tumor suppressor gene. In the last few years, galectin-3 has been found in a wide variety of malignances such as thyroid carcinoma, ${ }^{103}$ colon cancer $^{54}$ and tumors of the central nervous system. ${ }^{104}$ It has been observed that the metastatic potential of mouse melanoma and fibrosarcoma correlated with the extent of galectin-3 expression on the cell surface, and that overexpression of this protein conferred an increased metastatic potential to low metastatic cells. ${ }^{105}$ Galectin-3 probably acted by increasing the invasive potential in any step of the metastatic cascade, by virtue of its high affinity for the endothelium or its capacity to induce homotypic aggregation. ${ }^{102}$ In most cases, increased expression of galectin-3 rendered tumor cells more invasive and was associated with a worse survival.

Regarding galectin-1, sodium butyrate increased transcription of this $14.5 \mathrm{kDa}$ protein in head and neck squamous carcinoma. ${ }^{30}$ Furthermore, this proto-type galectin has been implicated in the modulation of human melanoma cell adhesion to laminin, ${ }^{62}$ suggesting that it could play a key role during attachment or detachment of cancer cells during tumor spreading. The contribution of other galectins to the metastatic process remains to be ascertained. Galectin-7, a marker of stratified epithelia and 
keratinocites has also been found to be present in human basal and spinous-cell carcinomas. ${ }^{106}$

The possibility that the interplay between galectins- 1 and -3 could be associated with control of the apoptotic threshold of cancer cells, must be considered in order to delineate novel therapeutic strategies. Strikingly, introduction of galectin-3 antisense into metastatic colon cancer cells, resulted in a significant reduction of liver colonization and spontaneous metastasis in athymic mice. ${ }^{54}$ Finally, an attractive hypothesis is that galectin- 1 expression in tumor cells (immune privileged sites) might have evolved as an apoptotic signal toward effector $\mathrm{T}$ cells, thus allowing tumors to escape immune attack.

\section{Galectins in pre-mRNA splicing: a short traverse to the nucleus}

If almost all known glycoconjugates are localized extracellularly, why have proteins supposed to interact with carbohydrates been designed as intracellular proteins? The answer remains largely obscure. However, recent advances have contributed to clarify this issue.

Galectin-1 and -3 have been found to be associated with ribonucleoprotein (RNP) complexes in NIH3T3 fibroblasts and HeLa cells at the level of the cell nucleus. ${ }^{35}$ These
RNP complexes are designed to structurally and functionally position pre-mRNA into spliceosomes for intron removal and exon ligation during production of mature transcripts, a process called splicing. Prompted by biochemical and ultrastructural observations, Dagher et $a l^{35}$ identified galectin-3 as a critical factor in pre-mRNA splicing. These observations were further extended to galectin-1. ${ }^{55}$ Depletion of both galectins from nuclear extracts by absorption with the specific saccharide, resulted in a concomitant loss of splicing activity. Moreover, either galectin-1 or galectin-3 alone were sufficient to reconstitute, at least partially, the splicing activity of depleted nuclear extracts. These proteins appeared to act at early stages in the splicing pathway, possibly those involved in the conversion of $\mathrm{H}$ complexes to commitment structures. ${ }^{107}$ Elucidation of the nuclear ligands will be critical for the understanding of this first intracellular function for galectins. A short but deep traverse to the nucleus!

\section{Concluding remarks: Where to go? Unknown dimensions and new frontiers}

Identification of homologous carbohydrate-binding proteins in lower vertebrates dates the existence of common ancestors
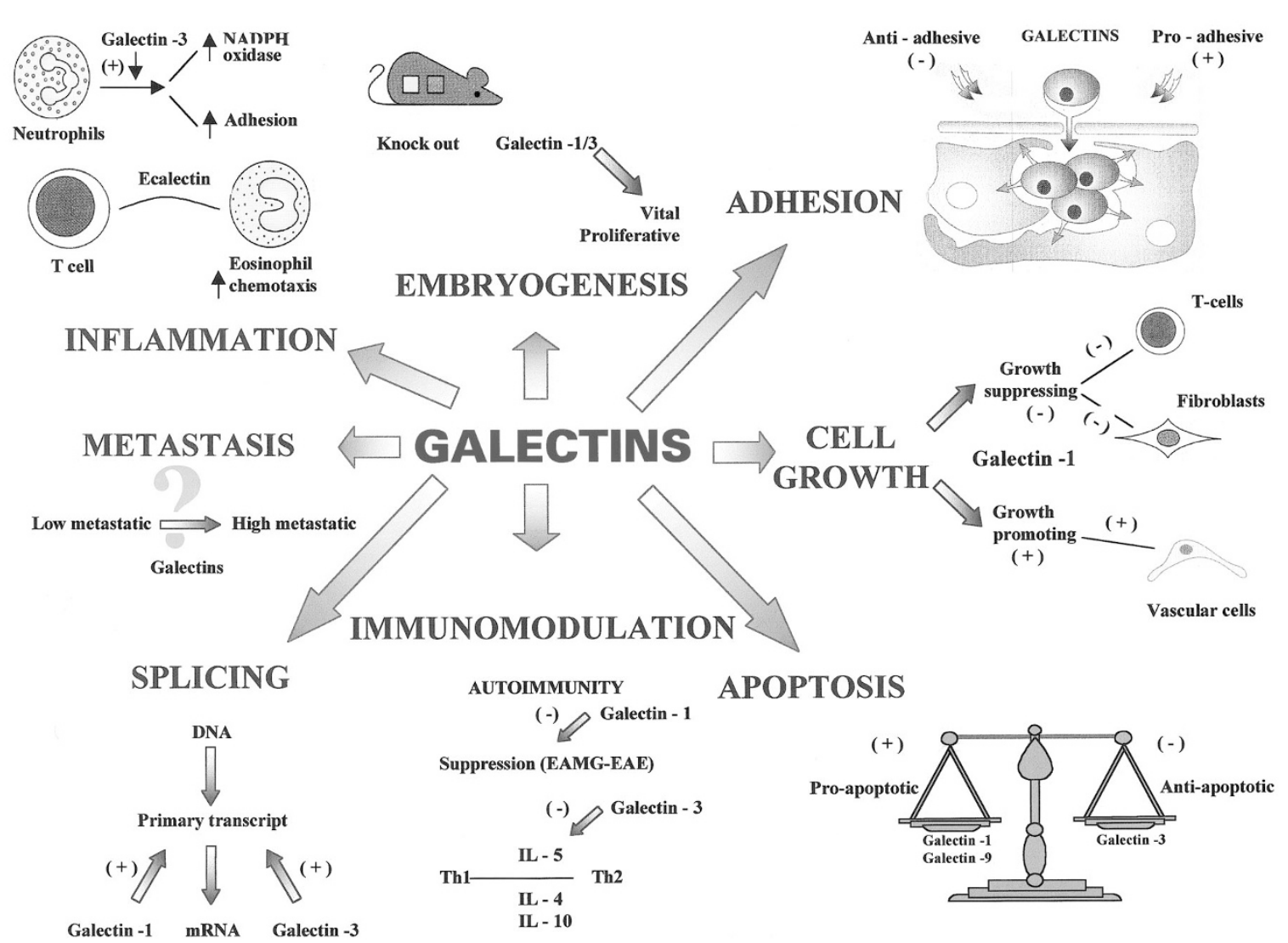

APOPTOSIS

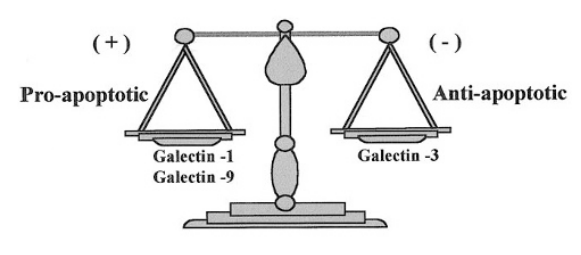

Figure 2 Galectins participate in a wide variety of biological events involving carbohydrate recognition, such as cell adhesion, cell growth regulation, apoptosis, immunomodulation, pre-mRNA splicing, metastasis, inflammation and embryogenesis, showing in most of the cases antagonic effects. Galectin functions are susceptible to modulation according to the glycosylation state of the receptors, cell activation status, developmentally regulated expression and subcellular compartmentalization. Abbreviations: EAMG, experimental autoimmune myasthenia gravis; EAE, experimental autoimmune encephalomyelitis 
for the galectin gene family to more than 800 million years ago, suggesting that these endogenous lectins must be serving important biological roles. Implication of galectins in a wide variety of functions, such as cell adhesion, cell growth regulation, immunomodulation, apoptosis, embryogenesis, metastasis and pre-mRNA splicing raises exciting perspectives.

Elucidation of the molecular mechanisms involved in galectin functions will open new avenues not only at the basic level of biomedical research, but more importantly in disease diagnosis, prognosis and clinical therapy. Future research should be aimed at identifying new strategies for the treatment of autoimmune diseases, inflammatory processes, allergic reactions and tumor spreading by using recombinant galectins, synthetic peptides, neutralizing antibodies or antisense oligonucleotides.

\section{Acknowledgements}

I would like to give special thanks to Drs. CM Riera, CA Landa and C Sotomayor for continuous support and to Dr. JL Bocco, M Romero and S Pesoa for critical reading of the manuscript. I am indebted to Dr. Ofer Lider (Rehovot) and Dr. Yuti Chernajovsky (London) who encouraged my work from its early stages and dedicate this work to Dr. M Depiante (may she rest in peace). I also thank all the people who collaborated with 'the galectin project' during the last few years: Drs. J Hirabayashi, K Kasai, CW Todel, M Iglesias, N Modesti, H Dreja, G Daily, G Chiabrando, C Alonso, L Castagna, S Correa and C Maldonado. This work was supported in part by grants from CONICET, CONICOR, Fundación Sales, Fundación Antorchas and British Council.

\section{References}

1. Barondes SH, Castronovo V, Cooper DNW, Cummings RD, Drickamer K, Feizi T, Gitt MA, Hirabayashi J, Hughes C, Kasai K, Leffler H, Liu F, Lotan R, Mercurio AM, Monsigni M, Pillai S, Poirer F, Raz A, Rigby PWJ, Rini JM and Wang JL (1994) Galectins: a family of animal galactoside-binding lectins. Cell 76: $597-$ 598

2. Barondes SH, Cooper DNW, Gitt MA and Leffler H (1994) Galectins: structure and function of a large family of animal lectins. J. Biol. Chem. 269: $20807-$ 20810

3. Kasai K and Hirabayashi J (1996) Galectins: a family of animal lectins that decipher glycocodes. J. Biochem. 119: 1-8

4. Leffler H (1997) Introduction to galectins. Trends Glycosci. Glycotechnol. 45: 9-19

5. Hirabayashi J and Kasai K (1993) The family of metazoan metal-independent $\beta$ galactoside-binding lectins: structure, function and molecular evolution. Glycobiology 3: 297-304

6. HirabayashiJ and KasaiK (1984) Human placenta $\beta$-galactoside-binding lectin. Purification and some properties. Biochem. Biophys. Res. Commun. 122: 938-944

7. Gitt MA and Barondes SH (1991) Genomic sequence and organization of two members of a human lectin gene family. Biochemistry 30: 82-89

8. Gitt MA, Massa SM, Leffler Hand Barondes SH (1992) Isolation and expression of a gene encoding L-14-II, a new human soluble lactose-binding lectin. J. Biol. Chem. 267: 10601-10606

9. Gitt MA, Wisers MF, Leffler H, Herrmann J, Xia Y-R, Massa SM, Cooper DNW, Luis AJ and Barondes SH (1995) Sequence and mapping of galectin-5, a $\beta$ galactoside-binding lectin, found in rat erithrocytes. J. Biol. Chem. 270: 50325038

10. Magnaldo T, Bernerd F and Darmon M (1995) Galectin-7, a human 14-kDa Slectin, specifically expressed in keratinocytes and sensitive to retinoic acid. Dev. Biol. 168: 259-271
11. Ackerman SJ, Corrette SE, Rosenberg HF, Bennet JC, Mastrianni DM, Nicholson-Weller A, Weller PF, Chin DT and Tenen DG (1993) Molecular cloning and characterization of human eosinophil Charcot-Leyden cristal protein (lysophospholipase). J. Immunol. 150: 456-468

12. Vasta GR, Ahmed H, Amzel LM and Bianchet MA (1997) Galectins from amphibian species: carbohydrate specificity, molecular structure and evolution. Trends Glycosci. Glycotechnol. 9: 131-144

13. Paroutaud P, Levi G, Teichberg VI and Strosberg AD (1987) Extensive amino acid homologies between animal lectins. Proc. Natl. Acad. Sci. USA 84: 63456348

14. Hirabayashi J, Ubukata T and Kasai K (1996) Purification and molecular characterization of a novel $16-\mathrm{kDa}$ galectin from the nematode Caenorhabditis elegans. J. Biol. Chem. 271: 2497-2505

15. Ohyama Y, Hirabayashi J, Oda Y, Oono S, Kawasaki H, Suzuki K and Kasai K (1986) Nucleotide sequence of chick $14 \mathrm{~K} \beta$-galactoside-binding lectin mRNA. Biochem. Biophys. Res. Commun. 134: 51-56

16. Sakakura Y, Hirabayashi J, Oda Y, Ohyama Y and Kasai K (1990) Structure of chicken $16-\mathrm{kDa} \beta$-galactoside-binding lectin: complete amino acid sequence, cloning of cDNA and production. J. Biol. Chem. 265: 21573-21579

17. Pfeifer K, Haasemann M, Gamulin V, Bretting $H$, Fahrenholz F and Muller WE (1993) S-type lectins occur also in invertebrates: high conservation of the carbohydrate recognition domain in the lectin genes from the marine sponge Geodia cydonium. Glycobiology 3: 179-184

18. Hughes RC (1994) Mac-2: a versatile galactose-binding protein of mammalian tissues. Glycobiology 4: 5-12

19. Nurminskaya M and Linsenmayer TF (1996) Identification and characterization of upregulated genes during chondrocyte hypertrophy. Dev. Dyn. 206: 260271

20. Oda Y, Herrmann J, Gitt MA, Turck CW, Burlingame AL, Barondes SH and Leffler H (1993) Soluble lactose-binding lectin from rat intestine with two different carbohydrate-binding domains in the same chain. J. Biol. Chem. 268: 5929-5939

21. Gitt MA, Colnot C, Poirier F, Nani KJ, Barondes SH and Leffler H (1998) Galectin- 4 and galectin- 6 are two closely related lectins expressed in mouse gastrointestinal tract. J. Biol. Chem. 273: 2954-2960

22. Hadari YR, Paz K, Dekel R, Mestrovic T, Accili D and Zick Y (1995) Galectin-8: a new rat lectin, related to galectin-4. J. Biol. Chem. 270: 3447-3453

23. Tureci O,Schmitt H, Fadle N, Pfreundschuh M and Sahin U (1997) Molecular definition of a novel human galectin which is immunogenic in patients with Hodgkin's disease. J. Biol. Chem. 272: 6416-6422

24. Rini JM (1995) Lectin structure. Annu. Rev. Biophys. Biomol. Struct. 24: 551 577

25. Liao DI, Kapadia G, Ahmed H, Vasta GR and Herzberg O (1994) Structure of Slectin, a developmentally regulated vertebrate $\beta$-galactoside-binding lectin. Proc. Natl. Acad. Sci. USA 15: 1428-1432

26. Brewer CF (1997) Cross-linking activities of galectins and other multivalent lectins. Trends Glycosci. Glycotechnol. 9: 155-165

27. Rabinovich GA, Castagna LF, Landa CA, Riera CM and Sotomayor CE (1996) Regulated expression of a 16-kd galectin-like protein in activated rat macrophages. J. Leuk. Biol. 59: 363-370

28. Cooper DNW (1997) Galectin-1: secretion and modulation of cell interactions with laminin. Trends Glycosci. Glycotechnol. 9: 57-67

29. Poirier F, Timmons PM, Chan C-T, GuenetJ-Land Rigby P (1992) Expression of the $L 14$ lectin during mouse embryogenesis suggests multiple roles during preand post-implantation development. Development 115: 143-155

30. Gillenwater A, Xu XC, Estrov Y, Sacks PG, Lotan D and Lotan R (1998) Modulation of galectin- 1 content in human head and neck squamous carcinoma cells by sodium butyrate. Int. J. Cancer 75: 217-224

31. Hsu DK, Hammes SR, Kuwabara I, Greene WC and Liu FT (1996) Human T lymphotropic virus-l infection of human $\mathrm{T}$ lymphocytes induces expression of the beta-galactoside binding lectin, galectin-3. J. Biol. Chem. 148: 1661 - 1670

32. Gaudin JC, Arar C, Monsigny M and Legrand A (1997) Modulation of the expression of the rabbit galectin-3 gene by $\mathrm{p} 53$ and $\mathrm{c}$-Ha-ras proteins and PMA. Glycobiology 7: 1089-1098

33. Sato $S$ and Hughes RC (1994) Regulation of secretion and surface expression of Mac-2, a galactoside-binding protein of macrophages. J. Biol. Chem. 269: 4424-4430 
34. Rabinovich GA, Iglesias MM, Modesti NM, Castagna LF, Wolfenstein-Todel C, Riera CM and Sotomayor CE (1998) Activated rat macrophages produce a galectin-1-like protein that induces apoptosis of $\mathrm{T}$ cells: biochemical and functional characterization. J. Immunol. 160: 4831-4840

35. Dagher SF, Wang JL and Patterson RJ (1995) Identification of galectin-3 as a factor in pre-mRNA splicing. Proc. Natl. Acad. Sci. USA 92: 1213-1217

36. Cleves AE, Cooper DN, Barondes SH and Kelly RB (1996) A new pathway for protein export in Saccharomyces cerevisiae. J. Cell Biol. 133: 1017-1026

37. Mehul B and Hughes RC (1997) Plasma membrane targetting, vesicular budding and release of galectin-3from the cytoplasm of mammalian cells during secretion. J. Cell Sci. 110: 1169-1178

38. Rubartelli A, Bajetto A, Allavena G, Wollman E and Sitia R (1992) Secretion of thioredoxin by normal and neoplastic cells through leaderless secretory pathway. J. Biol. Chem. 267: 24161-24164

39. Hubert M, Wang SY, Wang JL, Seve AP and Hubert J (1995) Intranuclear distribution of galectin-3 in mouse 3 T3 fibroblasts: comparative analyses by immunofluorescence and immunoelectron microscopy. Exp. Cell Res. 220: 397-406

40. Poirier F and Robertson EJ (1993) Normal development of mice carrying a null mutation in the gene encoding the L-14 S-type lectin. Development 119: 1229 1236

41. Colnot C, Fowlis D, Ripoche MA, Bouchaert I and Poirier F (1998) Embryonic implantation in galectin-1/galectin-3 double mutant mice. Dev. Dyn. 211:306313

42. Bourne Y, Bolgiano B, Liao D-I, Strecker G, Cantau P, Herzberg O, Feizi T and Cambillau C (1994) Crosslinking of mammalian lectin (galectin-1) by complex biantennary sugars. Nat. Struct. Biol. 1: 863-870

43. Hughes RC (1992) Lectins as cell adhesion molecules. Curr. Opin. Struct. Biol. 2: $687-692$

44. Wells $V$ and Mallucci $L$ (1991) Identification of an autocrine negative growth factor: mouse $\beta$-galactoside-binding protein is a cytostatic factor and cell growth regulator. Cell 64: 91-97

45. Adams L, Kenneth Scott $G$ and Weinberg C (1996) Biphasic modulation of cell growth by recombinant human galectin-1. Biochem. Biophys. Acta 1312: $137-$ 144

46. Levy G, Tarrab-Hazdai R and Teichberg VI (1983) Prevention and therapy with electrolectin of experimental autoimmune myasthenia gravis in rabbits. Eur. J. Immunol. 13: 500-507

47. Offner H, Celnik B, Bringman T, Casentini-Borocz D, Nedwin GE and Vandebark A (1990) Recombinant human $\beta$-galactoside-binding lectin suppresses clinical and histological signs of experimental autoimmune encephalomyelitis. J. Neuroimmunol. 28: 177-184

48. Perillo NL, Pace KE, Seilhamer JJ and Baum LG (1995) Apoptosis of T-cells mediated by galectin-1. Nature 378: 736-739

49. Yang RY, Hsu DK and Liu FT (1996) Expression of galectin-3 modulates T cell growth and apoptosis. Proc. Natl. Acad. Sci. USA 93: 6737-6742

50. YamaokaA, Kuwabaral, Frigeri LG and LiuFT (1995) A human lectin, galectin-3 (epsilon-BP/ Mac-2) stimulates superoxide production by neutrophils. J. Immunol. 154: 3479-3487

51. Iglesias MM, Rabinovich GA, Ambrosio AL, Castagna LF, Sotomayor CE and Wolfenstein-Todel CW (1998) Purification of galectin-3 from ovine placenta: developmentally regulated expression and immunological relevance. Glycobiology 8: 59-65

52. Iglesias MM, Rabinovich GA, Ivanovic V, Sotomayor CE and Wolfenstein-Todel C (1998) Galectin-1 from ovine placenta: amino-acid sequence, physicochemical properties and implications in T-cell death. Eur. J. Biochem. 252: 400-407

53. Raz A and Lotan R (1987) Endogenous galactoside-binding lectins: a new class of functional tumorcell surface molecules related to metastasis. Cancer Metast. Rev. 6: 433-452

54. Bresalier RS, Mazurek N, Sternberg LR, Byrd JC, Yunker CK, Makker PN and Raz A (1998) Metastasis of human colon cancer is altered by modifying expression of the $\beta$-galactoside binding protein galectin-3. Gastroenterology 115: $287-296$

55. Vyakarman A, Dagher SF, Wang JL and Patterson RJ (1997) Evidence for a role for galectin-1 in pre-mRNA splicing. Mol. Cell. Biol. 17: 4730-4737

56. Gilat D, Cahalon L, Hershkoviz R and Lider O (1996) Interplay of T cells and cytokines in the context of enzymatically modified extracellular matrix. Immunol. Today 17: 16-20
57. Zhou Q and Cummings RD (1993) L-14 lectin recognition of laminin and its promotion of in vitro cell adhesion. Arch. Biochem. Biophys. 300:6-17

58. Ozeki Y, Matsui T, Yamamoto Y, Funahashi M, Hamako J and Titani K (1995) Tissue fibronectin is an endogenous ligand for galectin-1. Glycobiology 5: $255-261$

59. Do K-Y, Smith DF and Cummings RD (1990) LAMP-1 in CHO cells is a primary carrier of poly- $\mathrm{N}$-acetyllactosamine chains and is bound preferentially by a mammalian S-type lectin. Biochem. Biophys. Res. Commun. 173: 1123-1128

60. Cooper DNW, Massa SM and Barondes SH (1991) Endogenous muscle lectin inhibits myoblast adhesion to laminin. J. Cell. Biol. 115: 1437-1448

61. Rabinovich GA, Ariel A, Hershkoviz R, Hirabayashi J, Kasai K and Lider O (1999) Specific inhibition of T-cell adhesion to extracellular matrix and proinflammatory cytokine secretion by human recombinant galectin-1. Immunology $97: 100-106$

62. Van den Brüle FA, Buicu C, Baldet M, Sobel ME, Cooper DNW, Marschal P and Castronovo V (1995) Galectin-1 modulates human melanoma cell adhesion to laminin. Biochem. Biophys. Res. Commun. 209: 760-767

63. Mahanthappa NK, Cooper DNW, Barondes SH and Schwarting GA (1994) Rat olfactory neurons can utilize the endogenous lectin L-14, in a novel adhesion mechanism. Development 120: 1373-1384

64. Kuwabara I and Liu F-T (1996) Galectin-3 promotes adhesion of human neutrophils to laminin. J. Immunol. 156: 3939-3944

65. Ochieng J, Leite-Browning ML and Warfield P (1998) Regulation of cellular adhesion to extracellular matrix proteins by galectin-3. Biochem. Biophys. Res. Commun. 246: 788-791

66. Osborne B (1996) Apoptosis and the maintenance of homeostasis in the immune system. Curr. Op. Immunol. 8: 245-254

67. Sandford GL and Harris-Hooker S (1990) Stimulation of vascular cell proliferation by $\beta$-galactoside-binding lectins. FASEB J. 4: 2912-2918

68. Roberts AB, Anzano MA, Wakefield LM, Roche NS, Stern DF and Sporn MB (1985) Type beta transforming growth factor: a bifunctional regulator of cell growth. Proc. Natl. Acad. Sci. USA 82: 119-123

69. Lynch DH, Ramsdell F and Alderson MR (1995) Fas and Fas L in the homeostatic regulation of immune responses. Immunol. Today 16: 569-574

70. Perillo NL, Uittenbogaart CH, Nguyen JT and Baum LG (1997) Galectin-1, an endogenous lectin produced by thymic epithelial cells, induces apoptosis of human thymocytes. J. Exp. Med. 97: 1851-1858

71. Lutomski D, Joubert-Caron R, Lefebure C, Salama J, Belin C, Bladier D and Caron M (1997) Anti-galectin-1 autoantibodies in serum of patients with neurological diseases. Clin. Chim. Acta. 262: 131-138

72. Ogden AT, Nunes I, Ko K, Wu S, Hines CS, Wang AF, Hegde RS and Lang RA (1998) GRIFIN, a novel lens-specific protein related to the galectin family. J. Biol. Chem. 273: 28889-28896

73. Griffith TS and Ferguson TA (1997) The role of Fas L-induced apoptosis in immune privilege. Immunol. Today 18: 240-244

74. Gold R, Hartung HP and Lassman H (1997) T-cell apoptosis in autoimmune diseases: termination of inflammation in the nervous system and other sites with specialized immune-defense mechanism. Trends Neurosci. 20: 399-404

75. Baum LG, Seilhamer JJ, Pang M, Levine WB, Beynon D and Berliner JA (1995) Synthesis of an endogenous lectin, galectin- 1 by human endothelial cells is upregulated by endothelial cell activation. Glycoconjugate J. 12: 63-68

76. Ahmed H, Fink NE, Pohl J and Vasta GR (1996) Galectin-1 from bovine spleen: biochemical characterization, carbohydrate specificity and tissue-specific isoform profiles. J. Biochem. 120: 1007-1019

77. Baum LG, Pang M, Perillo NL, Wu T, Delegaene A, Uittenbogaart CH, Fukuda M and SeilhamerJJ (1995) Human thymic epithelial cells express an endogenous lectin, galectin-1, which binds to core 2 O-glycans on thymocytes and T lymphoblastoid cells. J. Exp. Med. 181: 877-887

78. Blaser C, Kaufmann M, Muller C, Zimmerman C, Wells V, Mallucci L and Pircher $H$ (1998) $\beta$-galactoside-binding protein secreted by activated T cells inhibits antigen-induced proliferation of T cells. Eur. J. Immunol. 28: 2311-2319

79. Allione A, Wells V, Forni G., Mallucci $L$ and Novelli $F$ (1998) $\beta$-galactosidebinding protein ( $\beta$-GBP) alters the cell cycle, up-regulates expression of the $\alpha$ and $\beta$-chains of the IFN- $\gamma$ receptor, and triggers IFN- $\gamma$-mediated apoptosis of activated human T lymphocytes. J. Immunol. 161: 2114-2119

80. Cortegano I, del Pozo V, Cárdaba B, de Andres B, Gallardo S, del Amo A, Arrieta I, Jurado A, Palomino P, Liu F-T and Lahoz C (1998) Galectin-3 down-regulates IL-5 gene expression on different cell types. J. Immunol. 161: 385-389 
81. Swarte VV, Mebius RE, Joziasse DH, van den Eijnden DH and Kraal G (1998) Lymphocyte triggering via L-selectin leads to enhanced galectin-3-mediated binding to dendritic cells. Eur. J. Immunol. 28: 2846-2871

82. Goldstone SD and Lavin MF (1991) Isolation of a cDNA clone, encoding a human $\beta$-galactoside-binding protein overexpressed during glucocorticoidinduced cell death. Biochem. Biophys. Res. Commun. 178: 746-750

83. Steller H (1995) Mechanisms and genes of cellular suicide. Science 267: $1445-1449$

84. Vespa GN, Lewis LA, Kozak KR, Moran M, Nguyen JT, Baum LG and Miceli MC (1999) Galectin-1 specifically modulates TCR signals to enhance TCR apoptosis but inhibit IL-2 production and proliferation. J. Immunol. 162: 799 806

85. McFarland HL, Critchfield JM, Racke MK, Mueller JP, Nye SH, Boehme SA and Lenardo MJ (1995) Amelioration of autoimmune reactions by antigen-induced apoptosis of T cells. Adv. Exp. Med. Biol. 383: 157-166

86. Rabinovich GA, Modesti NM, Castagna LF, Landa CA, Riera CM and Sotomayor CE (1997) Specific inhibition of lymphocyte proliferation and induction of apoptosis by CLL-I, a $\beta$-galactoside-binding lectin. J. Biochem. 122: $365-373$

87. Cyster JG, Fowell D and Barclay AN (1994) Antigen determinants encoded by alternatively spliced exons of CD45 are determined by the polypeptide but influenced by glycosylation. Int. Immunol. 6: 1875-1881

88. Kröemer G (1997) The proto-oncogene Bcl-2 and its role in regulating apoptosis. Nat. Med. 3: 614-620

89. Akahani S, Nangia-Makker P, Inohara H, Choi Kim H-R and Raz A (1997) Galectin-3: a novel antiapoptotic molecule with a functional BH1 (NWGR) domain of Bcl-2 family. Cancer Res. 57: 5272-5276

90. Wada J, Ota K, Kumar A, Wallner El and Kanwar Y (1997) Developmental regulation, expression and apoptotic potential of galectin-9, a $\beta$-galactosidebinding lectin. J. Clin. Inv. 99: 2452-2461

91. Leenen PJM, Jansen MC and van Ewijk W (1986) Murine macrophage cell lines can be ordered in a linear differentiation sequence. Differentiation 32: 157-164

92. Avni O, Pur Z, Yefenof E and Baniyash M (1998) Complement receptor 3 of macrophages is associated with galectin-1-like protein. J. Immunol. 160: 6151-6158

93. Revillard JP, Adorini L, Goldman M, Kabelitz D and Waldmann H (1998) Apoptosis: potential for disease therapies. Immunol. Today 19: 291-293

94. Karlsson A, Follin P, Leffler H and Dahigren C (1998) Galectin-3 activates the NADPH oxidase in exudated but not peripheral blood neutrophils. Blood 91: $3430-3438$
95. ColnotC, Ripoche MA, Milon G, MontagutelliX, Crocker PRand PoirierF (1998) Maintenance of granulocyte numbers during acute peritonitis is defective in galectin-3-null mutant mice. Immunology 94: 290-296

96. Matsumoto R, Matsumoto H, Seki M, Hata M, Asano Y, Kanegasaki S, Stevens RL and Hirashima M (1998) Human ecalectin, a variant of human galectin-9, is a novel eosinophil chemoattractant produced by T lymphocytes. J. Biol. Chem. 273: $16976-16984$

97. Nachtigal M, Al-Assaad Z, Mayer EP, Kim K and Monsigny M (1998) Galectin-3 expression in human atherosclerotic lesions. Am. J. Pathol. 152: 1199-1208

98. Singer GG, Carrera AC, Marshak-Rothstein A, Martínez-A C and Abbas AK (1994) Apoptosis, Fas and systemic autoimmunity: the MRL-Ipr model. Curr. Opin. Immunol. 6: 913-920

99. Brian Kand Puche AC (1997) Role of galectin-1 in the olfactory nervous system. Trends Glycosci. Glycotechnol. 9: 41-45

100. Asano M, Furukawa K, Kido M, Matsumoto S, Umesaki $Y$, Kochibe $N$ and Iwakura $Y$ (1997) Growth retardation and early death of $\beta$-1,4-galactosyltransferase knockout mice with augmented proliferation and abnormal differentiation of epithelial cells. EMBO J. 16: 1850-1857

101. Lee VH, Lee AB, Phillips EB, Roberts JK and Weitlauf HM (1998) Spatiotemporal pattern for expression of galectin-3 in the murine utero-placental complex: evidence for differential regulation. Biol. Reprod. 58: 1277-1282

102. Akahani $S$, Inohara H, Nangia-Makker $P$ and Raz A (1997) Galectin-3 in tumor metastasis. Trends Glycosci. Glycotechnol. 9: 69-75

103. Xu XC, el-Naggar AK and Lotan R (1995) Differential expression of galectin-1 and galectin-3 in thyroid tumors. Potential diagnostic implications. Am. J. Pathol. 147: 815-822

104. Bresalier RS, Yan P-S, Byrd JC, Lotan R and Lotan R (1997) Expression of the endogenous galactose-binding protein galectin-3 correlates with malignant potential of tumors in the central nervous system. Cancer 80: 776-787

105. Raz A, Zhu DG, Hogan V, Shah N, Raz T, Karkash R, Pazerini G and Carmi P (1990) Evidence for the role of 34-kDa galectoside-binding lectin in transformation and metastasis. Int. J. Cancer 46: 871-877

106. Magnaldo T, Fowlis D and Darmon M (1998) Galectin-7, a marker of all stratified epithelia. Differentiation 63: 159-168

107. Patterson RJ, Dagher SF, Vyakarnam A and Wang JL (1997) Nuclear galectins: functionally redundant components in processing of pre-mRNA. Trends Glycosci. Glycotechnol. 9: 77-85 